\title{
Characterization of a Collection of Brassica carinata Genotypes for in vitro Culture Response and Mode of Shoot Regeneration
}

\author{
Javier Gil-Humanes, Antonio Martín, Francisco Barro
}

Institute for Sustainable Agriculture, CSIC. E-14080, Córdoba, Spain.

Email: javigil@ias.csic.es

Received August $5^{\text {th }}, 2010$; revised September 21 $1^{\text {st }}, 2010$; accepted September $28^{\text {th }}, 2010$.

\begin{abstract}
Brassica carinata, a natural alloploid formed between B. oleracea and B. nigra, is a potential oil crop for the Mediterranean area in which genetic transformation could help to breed. In vitro culture and shoot regeneration are key factors in developing an efficient transformation method in the genus Brassica. However, the studies for in vitro culture and shoot regeneration in B. carinata are limited to only a few genotypes. The aim of this study was to evaluate the in vitro culture response and shoot regeneration in a collection of B. carinata accessions to identify promising genotypes with high shoot regeneration for genetic transformation experiments. Cotyledonary explants from 51 genotypes were cultured in vitro and callus formation and swelling as well as the mode of shoot regeneration evaluated. A highly positive response to in vitro culture, i.e. callus formation or swelling, was observed in all the genotypes tested. Tissue blackening occurred only in eleven genotypes. Parameters like callus formation and swelling and number of shoots per explant were highly variable among genotypes. Fourteen genotypes regenerated only via callus formation, whereas only one regenerated only via swelling. Most genotypes showed a higher percentage of callus formation than swelling. The average number of shoots regenerating per explant among genotypes was the most variable factor measured. Six genotypes regenerated more than 6 shoots per explant via callus phase. These genotypes have been identified as having a high regeneration potential and can be used in genetic transformation via Agrobacterium.
\end{abstract}

Keywords: Mustard, Tissue Culture, Genotype, Cotyledons, Swelling, Callus

\section{Introduction}

Rapeseed (Brassica napus L.) is the third most important source of vegetable oil in the world with 31 million cultivated hectares in the year 2009 (FAOSTAT, 2011). Modification of the fatty acid composition is currently an important objective of plant breeding of this crop [1] and there is considerable commercial interest in the development of high erucic acid and/or low glucosinolates lines targeted toward industrial end-use and in the development of low (or zero) erucic acid, low linoleic and high oleic lines for food industries.

Ethiopian mustard, B. carinata A. Braun (BBCC, $2 \mathrm{n}=$ $4 \mathrm{x}=34)$, is a natural alloploid from B. oleracea $\mathrm{L}$. (CC, $2 \mathrm{n}=2 \mathrm{x}=18)$ and B. nigra (L.) W.D.J. Koch, $(\mathrm{BB}, 2 \mathrm{n}=$ $2 \mathrm{x}=16$ ) which has several agronomical important traits such as nondehiscent siliques and a much more developed and aggressive root system than B. napus. It is re- sistant to a wide range of diseases and pests and is tolerant to many abiotic stresses [2-4], which makes it a suitable candidate as a winter crop in the Mediterranean countries.

Plant transformation systems have been developed for many economically important species of the genus Brassica such as B. napus [5], B. oleracea [6], B. juncea [7], B. rapa [8], B. nigra [9] and B. carinata [10]. This technology enables us to obtain transgenic plants with modified agronomic traits. Many genetic improvements, such as herbicide tolerance, improved oil quality and production of pharmacological and industrial products, have been achieved by genetic transformation in the Brassica species. For example, B. napus seeds containing high levels of gamma-linoleic acid were obtained by the introduction of $\delta 12$-desaturase genes from the fungus Mortierella alpine [11]. In addition, B. napus genotypes were developed for sulfonylurea resistance and bro- 
moxynil resistance by Blackshaw et al. [12] and Zhong [13] respectively. In B. carinata, Jadhav et al. [14] increased the level of erucic acid in the seeds by co-suppression and antisense repression of the endogenous FAD2 gene encoding the oleate desaturase FAD2.

In vitro regeneration is a key factor in developing an efficient transformation method in plants. In vitro regeneration in Brassica ssp. is highly genotype-dependent as reported in previous studies for $B$. napus $[15,16], B$. juncea [17], B. rapa [18] and B. oleracea [19]. In addition, Dietert et al. [20] compared 6 species of the genus Brassica for callus growth and plant regeneration and reported a high influence of the genotype, with as much inter-cultivar as inter-species differences in the response to the in vitro culture. However, the available information for the genotype variability for in vitro culture and shoot regeneration in B. carinata is limited to a small number of genotypes. This genotype-dependence of the in vitro culture is a limiting factor for the application of genetic engineering to a wide number of genotypes. For that reason, it is important to identify highly regenerant genotypes that can be used in transformation via Agrobacterium tumefaciens.

This study aims to evaluate the in vitro culture response, i.e. callus formation and swelling, and the mode of shoot regeneration of a collection of B. carinata accessions to identify promising genotypes with high regeneration potential.

\section{Materials and Methods}

\subsection{Plant Material}

Fifty-one lines of $B$. carinata supplied by the Regional Plant Introduction Station (Iowa State University, Iowa, U.S.) (Table 1) were evaluated for in vitro culture and shoot regeneration response. For comparison, two lines were used as controls; a B. carinata DH line (BC71), which showed a good response to microspore culture [21] and a B. oleracea DH line (AG1012) provided by the Department of Crop Genetics (John Innes Centre, Norwich, UK) which was selected for its high regeneration and transformation potential [22].

\subsection{In vitro Culture}

Seeds were surface sterilized with $100 \%$ ethanol for 2 min and with a $15 \%$ sodium hypochlorite solution containing $0.1 \%$ Tween-20 for $15 \mathrm{~min}$. Then, seeds were washed 3 times with sterile distilled water and air-dried in flow hood chamber. Seeds were germinated in $15 \times 90$ $\mathrm{mm}$ Petri dishes containing $25 \mathrm{ml}$ of germination medium, which consisted of $4.3 \mathrm{~g} / 1 \mathrm{MS}$ salts [23] plus 3\% sucrose and $0.8 \%$ phytoagar at $\mathrm{pH} 5.8$. After autoclaving,
Table 1. List of Brassica. carinata genotypes used in the experiment supplied by the Regional Plant Introduction Station (Iowa State University, Iowa, U.S.). Genotypes are ordered by accession number.

\begin{tabular}{|c|c|c|c|c|}
\hline \multirow{2}{*}{$\begin{array}{c}\text { Code } \\
\text { number }\end{array}$} & \multirow{2}{*}{$\begin{array}{c}\text { Accession } \\
\text { number }\end{array}$} & \multicolumn{2}{|c|}{ Origin } & \multirow[b]{2}{*}{ Plant name } \\
\hline & & Country & State & \\
\hline 1 & 193459 & Ethiopia & Shewa & Unknown \\
\hline 2 & 193460 & Ethiopia & Harer & NU 51639 \\
\hline 3 & 193467 & Ethiopia & Shewa & NU 51640 \\
\hline 4 & 193759 & Ethiopia & Shewa & Unknown \\
\hline 5 & 193760 & Ethiopia & Shewa & NU 51642 \\
\hline 6 & 193959 & Ethiopia & Shewa & NU 51643 \\
\hline 7 & 194251 & Ethiopia & Kefa & NU 51645 \\
\hline 8 & 194252 & Ethiopia & Kefa & NU 51646 \\
\hline 9 & 194253 & Ethiopia & Kefa & NU 51647 \\
\hline 10 & 194254 & Ethiopia & Kefa & NU 51648 \\
\hline 11 & 194255 & Ethiopia & Kefa & NU 51649 \\
\hline 12 & 194900 & Ethiopia & Gonder & NU 51651 \\
\hline 13 & 194901 & Ethiopia & Gonder & Unknown \\
\hline 14 & 194903 & Ethiopia & Gonder & NU 51653 \\
\hline 15 & 194904 & Ethiopia & Gonder & Unknown \\
\hline 16 & 195552 & Ethiopia & Welo & NU 40525 \\
\hline 17 & 195923 & Ethiopia & Welo & NU 51657 \\
\hline 18 & 196836 & Ethiopia & Welega & Unknown \\
\hline 19 & 197402 & Ethiopia & Unknown & Unknown \\
\hline 20 & 197403 & Ethiopia & Unknown & NU 51660 \\
\hline 21 & 199947 & Ethiopia & Unknown & NU 51661 \\
\hline 22 & 199949 & Ethiopia & Gonder & NU 16543 \\
\hline 23 & 199950 & Ethiopia & Kefa & NU 51663 \\
\hline 24 & 209023 & Puerto Rico & Unknown & Unknown \\
\hline 25 & 226545 & Ethiopia & Shewa & NU 51664 \\
\hline 26 & 231046 & Ethiopia & Shewa & Unknown \\
\hline 27 & 273636 & Ethiopia & Harer & NU 51666 \\
\hline 28 & 273640 & Ethiopia & Shewa & Gomenzer \\
\hline 29 & 274283 & Ethiopia & Unknown & NU 51668 \\
\hline 30 & 280230 & Ethiopia & Unknown & NU $\quad 51669$ \\
\hline 31 & 331377 & Ethiopia & Unknown & Unknown \\
\hline 32 & 331378 & Ethiopia & Unknown & Unknown \\
\hline 33 & 360879 & Sweden & Unknown & $68-5702-1$ \\
\hline 34 & 360880 & Sweden & Unknown & $68-5702-4$ \\
\hline 35 & 360881 & Sweden & Unknown & $68-5702-6$ \\
\hline 36 & 360882 & Sweden & Unknown & $68-5702-10$ \\
\hline 37 & 360883 & Sweden & Unknown & $68-5702-16$ \\
\hline 38 & 360885 & Sweden & Unknown & 68-5702-12 PLT 1 \\
\hline 39 & 360886 & Sweden & Unknown & 68-5702-15 PLT $9 \mathrm{~S}$ \\
\hline 40 & 360887 & Sweden & Unknown & 68-5702-16 PLT $5 \mathrm{~S}$ \\
\hline 41 & 390133 & Pakistan & Unknown & P-1 \\
\hline 42 & 390134 & Pakistan & Unknown & P-58 \\
\hline 43 & 596535 & Spain & Cordoba & BC-815-2 \\
\hline 44 & 596536 & Spain & Cordoba & BC-876-2 \\
\hline 45 & 596537 & Spain & Cordoba & BC-738-5 \\
\hline 46 & 596538 & Spain & Cordoba & BC-834-2 \\
\hline 47 & 596539 & Spain & Cordoba & BC-831-2 \\
\hline 48 & 597822 & Sweden & Unknown & $85-0572-69$ \\
\hline 49 & 633075 & Tanzania & Unknown & Swahili \\
\hline 50 & 633076 & Kenya & Unknown & WIR 4325 \\
\hline 53 & 633080 & Zambia & Unknown & BRA 1028/79 \\
\hline
\end{tabular}


filtered vitamins myo-inositol $(100 \mathrm{mg} / \mathrm{l})$, thiamine- $\mathrm{HCl}$ $(10 \mathrm{mg} / \mathrm{l})$, pyridoxine $(1 \mathrm{mg} / \mathrm{l})$ and nicotinic acid $(1 \mathrm{mg} / \mathrm{l})$ were added to the medium. Seeds were sown at a density of 20-25 seeds per plate, incubated overnight at $15^{\circ} \mathrm{C}$ in the dark and then transferred to a culture room at $23^{\circ} \mathrm{C}$ under a 16 -h photoperiod of $70 \mu \mathrm{mol} \mathrm{m}^{-2} \mathrm{sec}^{-1}$ for $72 \mathrm{~h}$.

Cotyledons containing petioles of 1-2 $\mathrm{mm}$ in length were excised from 4-day-old seedlings and placed at a density of 10-11 cotyledons per plate into $20 \times 90 \mathrm{~mm}$ Falcon dishes containing $50 \mathrm{ml}$ of regeneration medium. This medium was the same germination medium described above plus $2 \mathrm{mg} / \mathrm{l}$ of 6-benzylaminopurine and $500 \mathrm{mg} / \mathrm{l}$ of carbenicillin. Explants were cultured in this regeneration medium for three weeks at $23^{\circ} \mathrm{C}$ under $16-\mathrm{h}$ photoperiod and then transferred onto fresh regeneration medium and subcultured for one week. Then, they were evaluated for blackening in the petiole, formation of callus or swelling in the base of the petiole and finally for the number of shoots produced via callus phase and via direct regeneration.

\subsection{Statistics}

Data was analyzed using the SPSS version 11.0 statistical software package. Arcsine $\sqrt{ } \mathrm{x}$ transformation was carried out on blackening, callus, swelling and no response frequencies before analysis. The General Analysis of Variance and the LSD pairwise comparisons of means were used to determine significant differences.

\section{Results}

Shoot regeneration from cotyledons in the genus Brassica can be produced via an indirect callus phase (Figure 1(a)). However, not all genotypes produce callus and, in some genotypes, direct shoot regeneration is observed via swelling at the petiole base (Figure 1(a)). The occurrence of blackening is thought to result from an interaction between the cut surface of the cotyledon petiole and the medium, and is highly genotype dependent (Figure 1(a)). The absence of tissue culture blackening is an important factor for transformation success in B. oleracea and B. napus $[22,24]$.

In this work we have evaluated the in vitro culture response, i.e. callus formation, swelling and blackening, and shoot regeneration in 51 genotypes of $B$. carinata and in two DH lines used as controls. Table 2 shows the results for all genotypes, indicating the number of cultivated explants, the explants with no response to in vitro culture, the explants with blackening, and the explants regenerating either via callus or via swelling at the base of the petiole.

Positive response to in vitro culture, as determined by callus formation or swelling of explants, was observed in

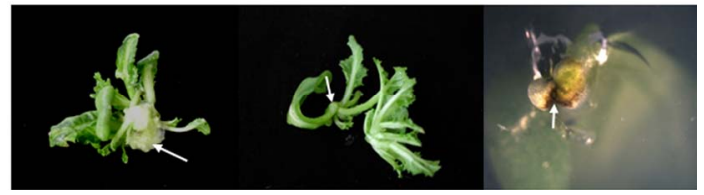

(a)

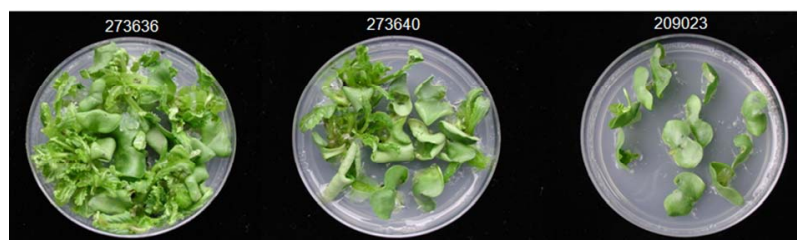

(b)

Figure 1. (a) Mode of shoot regeneration: callus formation (left), swelling at the base of the petiole (center) and tissue blackening (right). (b) Variability in number of shoots per explant regenerated via callus in three genotypes of Brassica carinata: 273636 (high number of shoots), 273640 (average number of shoots) and 209023 (low number of shoots).

all the genotypes tested (Table 2). In genotypes 4, 29, 31 and 1012, all the cultivated explants responded to in vitro culture, whereas genotypes 7, 18 and 41 showed the highest percentage of non-responding explants. Although genotypes showed regeneration both via callus and via swelling, most of the genotypes regenerated better via callus phase than via swelling, showing higher percentages of explants regenerating via callus than via swelling (Table 2). Only 7 genotypes $(7,8,9,10,12,14$ and 17) showed higher percentage of swelling than callus formation. The maximum percentage of explants producing swelling at the base of the petiole occurred in genotype 9 with $76.9 \%$, while the maximum percentage of callus formation occurred in genotype 29 with $100 \%$ of the explants responding via callus formation (Table 2). Tissue culture blackening occurred in $2.3 \%$ of the 2795 cultivated explants and affected 11 of the 53 genotypes tested. The maximum percentage of blackened explants was $34.6 \%$ for genotype 7 . This genotype also showed the highest percentage of non-responding explants $(57.7 \%)$ and all explants regenerated via swelling (Table 2).

Figure 2 shows the number of shoots per explant regenerated either via callus phase or via swelling phase (direct regeneration). The mean number of shoots per explant regenerated via callus was 2.9 , and the maximum value was observed in genotypes BC71 and 31 with 8.7 shoots per explant each. Six genotypes with more than 6 shoots per explant produced via callus were identified $(21,27,31,32,46$ and 71$)$ while twenty-five genotypes produced less than 2 shoots per explant. Figure 1B shows three genotypes with maximum, average and minimum shoot regeneration via callus phase. 
Table 2. In vitro culture response of cotyledonary explants from a collection of Brassica carinata and two DH lines: BC71 (Brassica carinata) and AG1012 (Brassica oleracea).

\begin{tabular}{|c|c|c|c|c|c|c|c|c|c|c|}
\hline \multirow{2}{*}{ Code number } & \multirow{2}{*}{ Accession number } & \multirow{2}{*}{ Number of explants } & \multicolumn{2}{|c|}{ No response } & \multicolumn{2}{|c|}{ Blackening } & \multicolumn{2}{|c|}{ Callus } & \multicolumn{2}{|c|}{ Swelling } \\
\hline & & & No. & $(\%)$ & No. & $(\%)$ & No. & $(\%)$ & No. & $(\%)$ \\
\hline 1 & 193459 & 66 & 2 & 3.0 & 0 & 0 & 55 & 83.3 & 9 & 13.6 \\
\hline 2 & 193460 & 47 & 5 & 10.6 & 0 & 0 & 36 & 76.6 & 6 & 12.8 \\
\hline 3 & 193467 & 63 & 10 & 15.9 & 0 & 0 & 35 & 55.6 & 18 & 28.6 \\
\hline 4 & 193759 & 50 & 0 & 0 & 0 & 0 & 39 & 78.0 & 11 & 22.0 \\
\hline 5 & 193760 & 64 & 3 & 4.7 & 12 & 18.8 & 61 & 95.3 & 0 & 0 \\
\hline 6 & 193959 & 46 & 3 & 6.5 & 0 & 0 & 38 & 82.6 & 5 & 10.9 \\
\hline 7 & 194251 & 26 & 15 & 57.7 & 9 & 34.6 & 0 & 0 & 11 & 42.3 \\
\hline 8 & 194252 & 28 & 4 & 14.3 & 5 & 17.9 & 11 & 39.3 & 13 & 46.4 \\
\hline 9 & 194253 & 39 & 7 & 17.9 & 7 & 17.9 & 2 & 5.1 & 30 & 76.9 \\
\hline 10 & 194254 & 49 & 10 & 20.4 & 0 & 0 & 13 & 26.5 & 26 & 53.1 \\
\hline 11 & 194255 & 40 & 1 & 2.5 & 0 & 0 & 37 & 92.5 & 2 & 5.0 \\
\hline 12 & 194900 & 38 & 4 & 10.5 & 0 & 0 & 7 & 18.4 & 27 & 71.1 \\
\hline 13 & 194901 & 52 & 3 & 5.8 & 0 & 0 & 46 & 88.5 & 3 & 5.8 \\
\hline 14 & 194903 & 41 & 7 & 17.1 & 0 & 0 & 13 & 31.7 & 21 & 51.2 \\
\hline 15 & 194904 & 47 & 15 & 31.9 & 1 & 2.1 & 22 & 46.8 & 10 & 21.3 \\
\hline 16 & 195552 & 57 & 12 & 21.1 & 0 & 0 & 42 & 73.7 & 3 & 5.3 \\
\hline 17 & 195923 & 27 & 5 & 18.5 & 0 & 0 & 5 & 18.5 & 17 & 63.0 \\
\hline 18 & 196836 & 45 & 25 & 55.6 & 0 & 0 & 20 & 44.4 & 0 & 0 \\
\hline 19 & 197402 & 50 & 3 & 6.0 & 0 & 0 & 44 & 88.0 & 3 & 6.0 \\
\hline 20 & 197403 & 39 & 2 & 5.1 & 0 & 0 & 36 & 92.3 & 1 & 2.6 \\
\hline 21 & 199947 & 48 & 6 & 12.5 & 0 & 0 & 42 & 87.5 & 0 & 0 \\
\hline 22 & 199949 & 29 & 8 & 27.6 & 0 & 0 & 19 & 65.5 & 2 & 6.9 \\
\hline 23 & 199950 & 38 & 1 & 2.6 & 1 & 2.6 & 29 & 76.3 & 8 & 21.1 \\
\hline 24 & 209023 & 65 & 11 & 16.9 & 0 & 0 & 48 & 73.8 & 6 & 9.2 \\
\hline 25 & 226545 & 29 & 3 & 10.3 & 4 & 13.8 & 24 & 82.8 & 2 & 6.9 \\
\hline 26 & 231046 & 33 & 5 & 15.2 & 0 & 0 & 28 & 84.8 & 0 & 0 \\
\hline 27 & 273636 & 55 & 2 & 3.6 & 0 & 0 & 53 & 96.4 & 0 & 0 \\
\hline 28 & 273640 & 51 & 5 & 9.8 & 0 & 0 & 46 & 90.2 & 0 & 0 \\
\hline 29 & 274283 & 61 & 0 & 0 & 0 & 0 & 61 & 100.0 & 0 & 0 \\
\hline 30 & 280230 & 60 & 2 & 3.3 & 4 & 6.7 & 58 & 96.7 & 0 & 0 \\
\hline 31 & 331377 & 58 & 0 & 0 & 0 & 0 & 53 & 91.4 & 5 & 8.6 \\
\hline 32 & 331378 & 63 & 5 & 7.9 & 0 & 0 & 49 & 77.8 & 9 & 14.3 \\
\hline 33 & 360879 & 56 & 7 & 12.5 & 0 & 0 & 47 & 83.9 & 2 & 3.6 \\
\hline 34 & 360880 & 59 & 6 & 10.2 & 0 & 0 & 49 & 83.1 & 4 & 6.8 \\
\hline 35 & 360881 & 50 & 12 & 24.0 & 0 & 0 & 36 & 72.0 & 2 & 4.0 \\
\hline 36 & 360882 & 65 & 6 & 9.2 & 0 & 0 & 55 & 84.6 & 4 & 6.2 \\
\hline 37 & 360883 & 58 & 17 & 29.3 & 0 & 0 & 41 & 70.7 & 0 & 0 \\
\hline 38 & 360885 & 54 & 2 & 3.7 & 4 & 7.4 & 46 & 85.2 & 6 & 11.1 \\
\hline 39 & 360886 & 63 & 12 & 19.0 & 0 & 0 & 50 & 79.4 & 1 & 1.6 \\
\hline 40 & 360887 & 66 & 6 & 9.1 & 0 & 0 & 60 & 90.9 & 0 & 0 \\
\hline 41 & 390133 & 65 & 23 & 35.4 & 0 & 0 & 42 & 64.6 & 0 & 0 \\
\hline 42 & 390134 & 66 & 2 & 3.0 & 0 & 0 & 52 & 78.8 & 12 & 18.2 \\
\hline 43 & 596535 & 33 & 5 & 15.2 & 0 & 0 & 25 & 75.8 & 3 & 9.1 \\
\hline 44 & 596536 & 39 & 3 & 7.7 & 9 & 23.1 & 36 & 92.3 & 0 & 0 \\
\hline 45 & 596537 & 48 & 15 & 31.3 & 0 & 0 & 33 & 68.8 & 0 & 0 \\
\hline 46 & 596538 & 66 & 5 & 7.6 & 0 & 0 & 59 & 89.4 & 2 & 3.0 \\
\hline 47 & 596539 & 64 & 8 & 12.5 & 0 & 0 & 53 & 82.8 & 3 & 4.7 \\
\hline 48 & 597822 & 76 & 6 & 7.9 & 0 & 0 & 63 & 82.9 & 7 & 9.2 \\
\hline 49 & 633075 & 53 & 5 & 9.4 & 0 & 0 & 42 & 79.2 & 6 & 11.3 \\
\hline 50 & 633076 & 44 & 4 & 9.1 & 0 & 0 & 36 & 81.8 & 4 & 9.1 \\
\hline 53 & 633080 & 95 & 15 & 15.8 & 0 & 0 & 74 & 77.9 & 6 & 6.3 \\
\hline 71 & BC71 & 44 & 5 & 11.4 & 0 & 0 & 39 & 88.6 & 0 & 0 \\
\hline 1012 & AG1012 & 127 & 0 & 0 & 3 & 2.4 & 100 & 78.7 & 27 & 21.3 \\
\hline
\end{tabular}




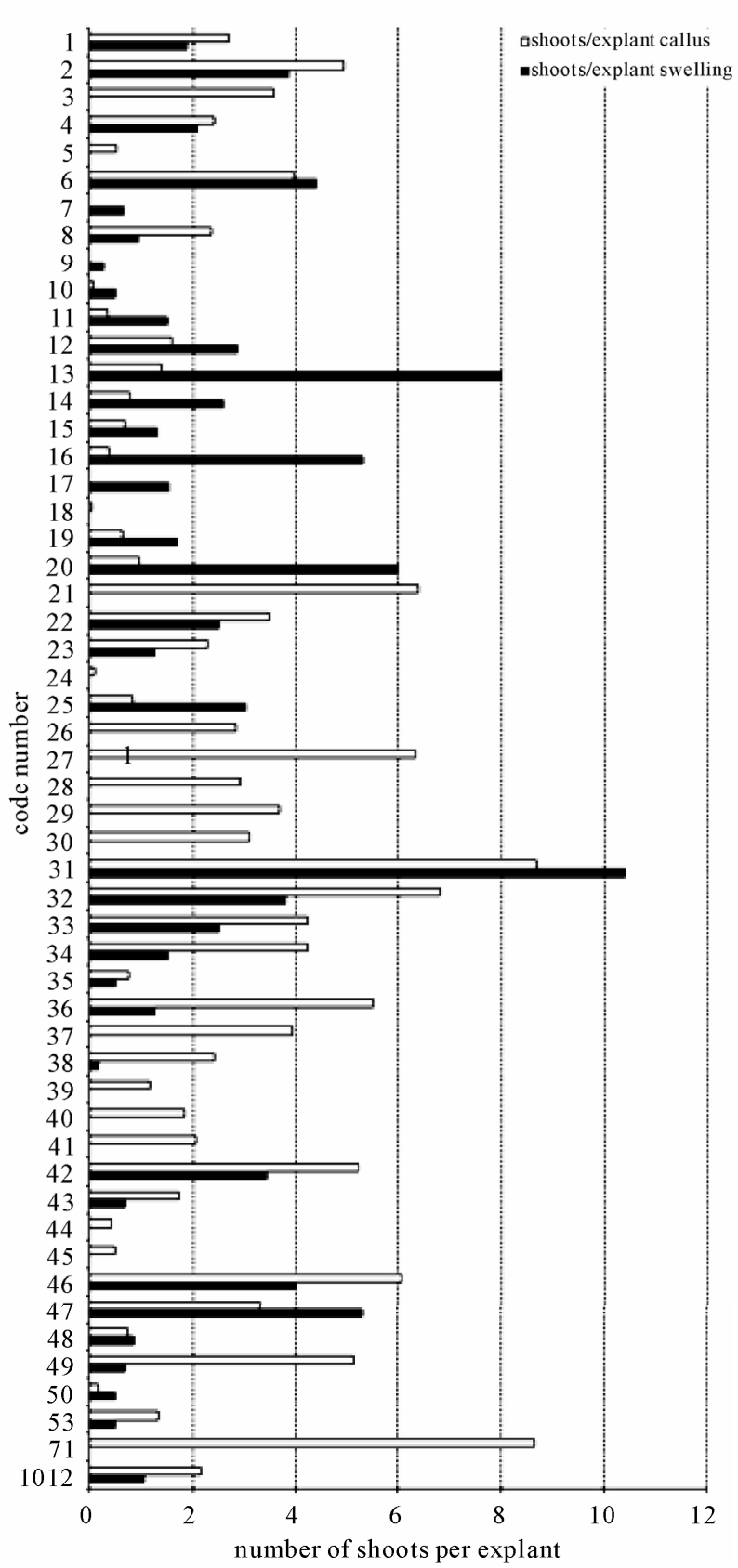

Figure 2 Number of shoots per explant regenerated via callus or swelling from cotyledonary explants collected from 51 lines of Brassica carinata. Two DH lines, BC71 (Brassicca carinata) and AG1012 (Brassica oleracea) were included for comparison.

The mean number of shoots regenerated via swelling was 1.7, and the genotype producing the maximum number of shoots per explant was also genotype 31 with 10.4 shoots per explant. Only three genotypes $(20,13$ and 31) produced more than 6 shoots per explant by direct regeneration while thirty-seven genotypes produced less than 2 shoots per explant.

In thirty-two genotypes, shoots were produced both by callus and swelling phase, whereas seventeen genotypes regenerated shoots only by callus phase and in genotypes 7,9 and 17 all the shoots were regenerated by direct regeneration.

General analysis of variance (Table 3) revealed that there were highly significant differences among genotypes for the absence of response to the in vitro culture, the mode of response, i.e. percentage of callus or percentage of swelling, the occurrence of blackening, and the number of shoots produced either via callus or via direct regeneration.

\section{Discussion}

Shoot regeneration in B. carinata can occur directly from explant tissue as well as indirectly from callus that proliferate from the cut edge of the explants. In many genotypes, direct shoot regeneration has been described as less genotype dependent [25] and regenerants show more genetic stability [26], whereas callus phase is more associated with somaclonal variation. However, direct shoot regeneration has limitations in being used for DNA transfer as totipotent cells are less accessible to Agrobacterium during cocultivation [27]. In fact, dedifferentiation of explant cells into callus was necessary for the efficient transformation of B. carinata [10]. Therefore, the identification of genotypes with high regeneration potential that regenerate mostly via callus formation can largely influence the recovery of transgenic plants. Sparrow et al. [22] found three phenotypic markers highly influencing the transformation efficiency in B. oleracea. These are: susceptibility to A. tumefaciens [28], shoot regeneration potential and the mode of shoot regenera

Table 3. Analysis of variance for in vitro culture response and shoot regeneration in a collection of Brassica carinata accessions. Values expressed as a percentage were transformed using the arcsine $\sqrt{ } \mathbf{x}$ function for the analysis of variance.

\begin{tabular}{cccc}
\hline Parameter & MS & $d f$ & F-test \\
\hline No response (\%) & 0.1298 & 52 & $3.48^{* * *}$ \\
Blackening (\%) & 0.0476 & 52 & $3.14^{* * *}$ \\
Callus (\%) & 0.1865 & 52 & $4.61^{* * *}$ \\
Swelling (\%) & 0.1617 & 52 & $4.90^{* * *}$ \\
Shoots per explant from callus & 19.742 & 51 & $10.00^{* * *}$ \\
Shoots per explant from swelling & 15.596 & 38 & $2.16^{* *}$ \\
\hline
\end{tabular}

Significance probability levels: $* * 1 \%, * * * 0.1 \%$. MS; Mean Square, $d f$; degree of freedom. 
tion. They also found that the absence of blackening tissue associated with callus formation is critical for transformation success. We have applied these criteria to evaluate a collection of 51 genotypes of $B$. carinata for in vitro culture and shoot regeneration potential, including the mode of shoot regeneration. We have found a highly positive response to in vitro culture, i.e. callus formation and swelling, in all the genotypes tested in this study. Other studies have previously confirmed the responsiveness of $B$. carinata seedling explants to tissue culture [29-31]. For both, callus formation and swelling, there were significant differences among genotypes. In our study, the number of genotypes that proliferate via callus formation was much higher than those via swelling. In addition, the percentage of callus formation was higher than swelling in all the genotypes, except in 7 genotypes $(7,8,9,10,12,14$ and 17) in which the percentage of swelling formation was higher.

Callus formation at the base of the petiole has been demonstrated to be an interesting trait in obtaining a great number of shoots per explant. Sparrow et al. [22] observed that shoot regeneration via the callus phase resulted in well established and morphologically defined shoots that were easy to isolate and propagate. Results reported here showed that shoot production was very variable among genotypes. This result agreed with studies in Brassica spp., which also reported that shoot production was highly variable among different genotypes, indicating that the regeneration ability is strongly influenced by genotype [15-20]. Zhang et al. [18] reported a maximum of 10.7 shoots per explant in a cultivar of Chinese cabbage. In our study the maximum number of shoots per explant was 8.7 and 10.4, regenerated respectively from callus and direct regeneration, both by genotype 31 . We have found six genotypes $(21,27,31,32,46$ and 71) producing more than 6 shoots per explant via callus formation, although three of them (31, 32 and 46) also produced shoots via swelling. These six genotypes had a percentage of callus formation between $77.8 \%$ and $96.4 \%$ and no blackening tissue at the base of the petiole was observed. These six genotypes produced an average of 7.1 shoots per explant via callus. This average is 2.4 times higher than the 2.9 shoots of average produced via callus by all genotypes. This high-frequency of regeneration from callus might be of great importance in regeneration of transgenic plants. Mukhopadyay et al. [27] reported that the transformation frequency of B. campestris is strongly influenced by the mode of shoot regeneration. In addition, Babic et al. [10] reported that efficient regeneration from callus was responsible for the high frequency of transformation in B. carinata.

The occurrence of tissue blackening resulted from an interaction between the cut surface of the cotyledon petiole and the medium. Although blackening does not prevent the formation of shoots, we have observed a negative correlation between the percentage of blackening and the number of shoots per explant. In addition, genotypes with no blackening produce more shoots than those presenting blackening. Therefore, the absence of tissue blackening influences the successful regeneration of shoots and this could be a critical factor to regenerate transgenic plants.

In conclusion, in this work we have characterized the tissue culture response and the mode of regeneration of a collection of B. carinata. The mode of shoot regeneration is important in the selection of genotypes with a high regeneration potential and that regenerate mainly from callus. Six genotypes $(21,27,31,32,46$ and 71$)$ have been identified as having a high regeneration potential. They produce the highest number of shoots per explant via callus formation and do not present tissue blackening at the base of the petiole. We are currently incorporating these 6 genotypes in transformation experiments to determine their susceptibility to A. tumefaciens. The results of these experiments should allow us to develop a transformation program using genotypes highly susceptible to A. tumefaciens and with a high level of regeneration via callus.

\section{Acknowledgments}

The authors acknowledge funding by the Spanish Comisión Interministerial de Ciencia y Tecnología (C.I.C.Y.T.), project AGL2004-03361-C02-2 and to the Regional Plant Introduction Station (Iowa State University, Iowa, U.S.) for supplying seeds. Javier Gil-Humanes acknowledges the CSIC for a pre-doctoral I3P fellowship and to Dr. Penelope Sparrow from the Crop Genetics Department of John Innes Center (UK) for the critical reading of the manuscript. Technical assistance by Azahara Vida is also acknowledged.

\section{REFERENCES}

[1] W. Friedt and W. Luhs, "Recent Developments and Perspectives of Industrial Rapeseed Breeding," Fett-Lipid, Vol. 100, No. 6, June 1998, pp. 219-226. doi:10.1002/(SICI)1521-4133(199806)100:6<219::AID-L IPI219>3.0.CO;2-Y

[2] R. K. Katiyar, G. Saran and G. Giri, "Evaluation of Brassica carinata as a New Oilseed Crop in India," Experimental Agriculture, Vol. 22, No. 1, January 1986, pp. 67-70. doi:10.1017/S0014479700014058

[3] A. Getinet, G. Rakow and R. K. Downey, "Agronomic Performance and Seed Quality of Ethiopian Mustard in Saskatchewan," Canadian Journal of Plant Science, Vol. 
76, No. 3, July 1996, pp. 387-392.

[4] R. S. Malik, "Prospects for Brassica carinata as an Oilseed Crop in India," Experimental Agriculture, Vol. 26, No. 1, January 1990, pp. 125-129. doi:10.1017/S0014479700015465

[5] M. M. Moloney, J. M. Walker and K. K. Sharma, "High Efficiency Transformation of Brassica napus Using Agrobacterium Vectors," Plant Cell Reports, Vol. 8, No. 4, July 1989, pp. 238-242. doi:10.1007/BF00778542

[6] M. Deblock, D. Debrouwer and P. Tenning, "Transformation of Brassica napus and Brassica oleracea Using Agrobacterium tumefaciens and the Expression of the bar and neo Genes in the Transgenic Plants," Plant Physiology, Vol. 91, No. 2, October 1989, pp. 694-701. doi:10.1104/pp.91.2.694

[7] D. G. Barfield and E. C. Pua, "Gene Transfer in Plants of Brassica juncea using Agrobacterium tumefaciens Mediated Transformation," Plant Cell Reports, Vol. 10, No. 6-7, September 1991, pp. 308-314. doi:10.1007/BF00193148

[8] S. E. Radke, J. C. Turner and D. Facciotti, "Transformation and Regeneration of Brassica rapa Using Agrobacterium tumefaciens," Plant Cell Reports, Vol. 11, No. 10, September 1992, pp. 499-505. doi:10.1007/BF00236265

[9] V. Gupta, G. L. Sita, M. S. Shaila and V. Jagannathan, "Genetic Transformation of Brassica nigra by Agrobacterium Based Vector and Direct Plasmid Uptake," Plant Cell Reports, Vol. 12, No. 7-8, May 1993, pp. 418-421.

[10] V. Babic, R. S. Datla, G. J. Scoles and W. A. Keller, "Development of an Efficient Agrobacterium-Mediated Transformation System for Brassica carinata," Plant Cell Reports, Vol. 17, January 1998, pp. 183-188. doi:10.1007/s002990050375

[11] J. W. Liu, S. DeMichele, M. Bergana, E. Bobik, C. Hastilow, L. T. Chuang, P. Mukerji and Y. S. Huang, "Characterization of Oil Exhibiting High Gamma-Linolenic Acid from a Genetically Transformed Canola Strain," Journal of the American Oil Chemists Society, Vol. 78, No. 5, May 2001, pp. 489-493. doi:10.1007/s11746-001-0291-2

[12] R. E. Blackshaw, D. Kanashiro, M. M. Moloney and W. L. Crosby, "Growth, Yield and Quality of Canola Expressing Resistance to Acetolactate Synthase Inhibiting Herbicides," Canadian Journal of Plant Science, Vol. 74, No. 4, October 1994, pp. 745-751.

[13] R. Z. Zhong, F. Zhu, Y. L. Liu, S. G. Li, L. Y. Kang and P. Luo, "Oilseed Rape Transformation and the Establishment of a Bromoxynil-Resistant Transgenic Oilseed Rape," Acta Botanica Sinica, Vol. 39, September 1997, pp. 22-27.

[14] A. Jadhav, V. Katavic, E. F. Marillia, E. M. Giblin, D. L. Barton, A. Kumar, C. Sonntag, V. Babic, W. A. Keller and D. C. Taylor, "Increased Levels of Erucic Acid in Brassica carinata by Co-suppression and Antisense Repression of the Endogenous FAD2 Gene," Metabolic Engineering, Vol. 7, No. 3, May 2005, pp. 215-220.

\section{doi:10.1016/j.ymben.2005.02.003}

[15] Y. Ono, Y. Takahata and N. Kaizuma, "Effect of Genotype on Shoot Regeneration from Cotyledonary Explants of Rapeseed (Brassica napus L.)," Plant Cell Reports, Vol. 14, No. 1, November 1994, pp. 13-17. doi:10.1007/BF00233290

[16] S. K. Phogat, P. K. Burma and D. Pental, "High Frequency Regeneration of Brassica napus Varieties and Genetic Transformation of Stocks Containing Fertility Restorer Genes for Two Cytoplasmic Male Sterility Systems," Journal of Plant Biochemistry and Biotechnology, Vol. 9, No. 2, July 2000, pp. 73-79.

[17] D. Pental, A. K. Pradhan, Y. S. Sodhi and A. Mukhopadhyay, "Variation amongst Brassica juncea Cultivars for Regeneration from Hypocotyl Explants and Optimization of Conditions for Agrobacterium Mediated Genetic Transformation," Plant Cell Reports, Vol. 12, No. 7-8, May 1993, pp. 462-467. doi:10.1007/BF00234713

[18] F. L. Zhang, Y. Takahata and J. B. Xu, "Medium and Genotype Factors Influencing Shoot Regeneration from Cotyledonary Explants of Chinese Cabbage (Brassica campestris L. ssp. pekinensis)," Plant Cell Reports, Vol. 17 , No. 10, July 1998 , pp. 780-786. doi: $10.1007 / \mathrm{s} 002990050482$

[19] P. A. C. Sparrow, T. M. Townsend, C. L. Morgan, P. J. Dale, A. E. Arthur and J. A. Irwin, "Genetic Analysis of in vitro Shoot Regeneration from Cotyledonary Petioles of Brassica oleracea," Theoretical and Applied Genetics, Vol. 108, No. 7, May 2004, pp. 1249-1255. doi:10.1007/s00122-003-1539-y

[20] M. F. Dietert, S. A. Barron and O. C. Yoder, "Effects of Genotype on in vitro Culture in the Genus Brassica," Plant Science Letters, Vol. 26, No. 2-3, August 1982, pp. 233-240. doi:10.1016/0304-4211(82)90096-7

[21] F. Barro and A. Martín, "Response of Different Genotypes of Brassica carinata to Microspore Culture," Plant Breeding, Vol. 118, No. 1, March 1999, pp. 79-81. doi:10.1046/j.1439-0523.1999.118001079.x

[22] P. A. C. Sparrow, P. J. Dale and J. A. Irwin, "The Use of Phenotypic Markers to Identify Brassica oleracea Genotypes for Routine High-Throughput Agrobacterium-mediated transformation," Plant Cell Reports, Vol. 23, No. 1-2, August 2004, pp. 64-70. doi:10.1007/s00299-004-0818-7

[23] T. Murashige and F. Skoog, "A Revised Medium for Rapid Growth and Bio Assays with Tobacco Tissue Cultures," Physiologia Plantarum, Vol. 15, No. 3, July 1962, pp. 473-497. doi:10.1111/j.1399-3054.1962.tb08052.x

[24] P. A. C. Sparrow, J. W. Snape, P. J. Dale and J. A. Irwin, "The Rapid Identification of B. napus Genotypes, for High-Throughput Transformation, Using Phenotypic Tissue Culture Markers," Acta Horticulture, Vol. 706, April 2006, pp. 239-247.

[25] O. Toldi, G. Gyulai, J. Kiss, I. A. Tamas and E. Balazs, "Antiauxin Enhanced Microshoot Initiation and Plant Regeneration from Epicotyl-Originated Thin-Layer Ex- 
plants of sugarbeet (Beta vulgaris L.)," Plant Cell Reports, Vol. 15, No. 11, August 1996, pp. 851-854. doi:10.1007/BF00233155

[26] C. Detrez, R. S. Sangwan and B. S. Sangwannorreel, "Phenotypic and Karyotypic Status of Beta vulgaris Plants Regenerated from Direct Organogenesis in Petiole Culture," Theoretical and Applied Genetics, Vol. 77, No. 4, April 1989, pp. 462-468. doi:10.1007/BF00274264

[27] A. Mukhopadhyay, N. Arumugam, P. B. A. Nandakumar, A. K. Pradhan, V. Gupta and D. Pental, "Agrobacterium Mediated Genetic Transformation of Oilseed Brassica campestris Transformation Frequency is Strongly Influenced by the Mode of Shoot Regeneration," Plant Cell Reports, Vol. 11, No. 10, September 1992, pp. 506-513. doi:10.1007/BF00236266

[28] P. A. C. Sparrow, T. M. Townsend, A. E. Arthur, P. J. Dale and J. A. Irwin, "Genetic Analysis of Agrobacterium
Tumefaciens Susceptibility in Brassica oleracea," Theoretical and Applied Genetics, Vol. 108, No. 4, February 2004, pp. 644-650. doi:10.1007/s00122-003-1473-Z

[29] S. B. Narasimhulu and V. L. Chopra, "Plant Regeneration from Callus Cultures of Brassica carinata A. Br. and Its Implications to Improvement of Oil Seed Brassicas," Plant Breeding, Vol. 99, No. 1, September 1987, pp. 49-55. doi:10.1111/j.1439-0523.1987.tb01149.x

[30] S. B. Narasimhulu and V. L. Chopra, "Species Specific Shoot Regeneration Response of Cotyledonary Explants of Brassicas," Plant Cell Reports, Vol. 7, No. 2, March 1988, pp. 104-106. doi:10.1007/BF00270115

[31] M. Z. Yang, S. R. Jia and E. C. Pua, "High Frequency of Plant Regeneration from Hypocotyl Explants of Brassica carinata A. Br.," Plant Cell Tissue and Organ Culture, Vol. 24, No. 2, February 1991, pp. 79-82. doi:10.1007/BF00039734 